\title{
A SIMPLIFIED SPEED CONTROLLER FOR HIGH SPEED SWITCHED RELUCTANCE MOTORS
}

\author{
Ahmed Said Oshaba, M. M. SALEM \\ 1. Electronics Research Institute, Power Electronics and Energy Conversions \\ NRC Blg., El-Tahrir St., Dokki, 12311-Giza, Egypt \\ 2. Jizan University, Faculty of Engineering, Electrical Engineering Department, KSA \\ E-Mail: oshaba68@hotmail.com,masalam32@yahoo.com
}

\begin{abstract}
This paper presents a simplified speed controller (SSC) for high speed Switched Reluctance Motors (SRM). The controller is designed to overcome difficulties estimating control variables and motor operation over a wide range of speeds. The controller combines the advantages of the simplicity of conventional controllers and the intelligent properties of the fuzzy logic controller. The controller use only two control variables which are calculated via the perturbation of the mechanical equation and pre-defined SRM speed performance. The controller is designed and implemented by computer simulation. The performance of the motor with the controller is assessed using dynamic loads and various types of disturbances. The results illustrate that the controller represent an ultimate solution for the operation of high speed switched reluctance motors.
\end{abstract}

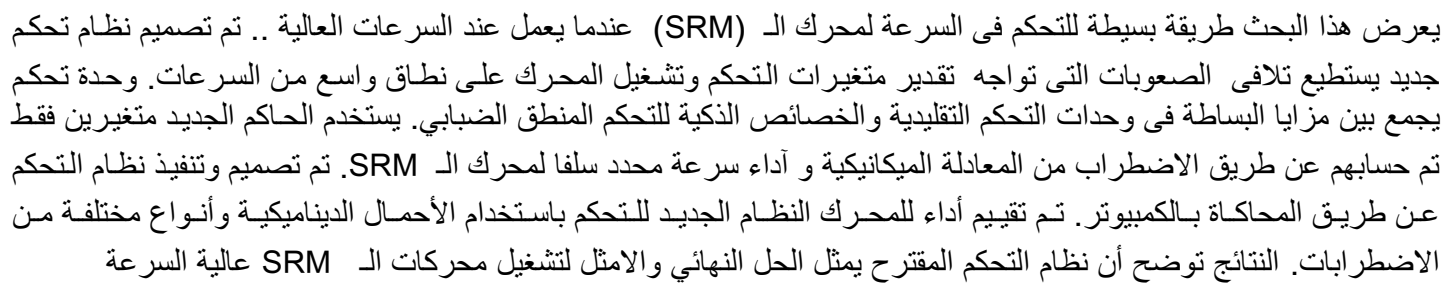

Keywords: High speed SRM, Variable Speed drives, Control of SRM.

\section{1- Introduction}

The development of high performance motor drives is very important in industrial application. Many techniques have been developed and applied to control the speed of the high speed SRM drive applications and important results were published [1-4]. The popular and dominant approach for speed control in industrial drives use a proportional plus integral (PI) controller. However, the PI controller does not provide improve the SRM performance instantaneously due to fast variation nature of operation parameters in this type of motors[5]. Recent developments in artificial intelligent based control have brought into focus a possibility of replacing the conventional PI speed controller with a Fuzzy Logic equivalent [6]. Fuzzy logic (FL) speed control sometimes seems as the ultimate solution for high-performance drives of the next generation [7]. Such a prediction of future trends is based on a comparison of the drive response under PI and FL speed control, which has been compared on a number of occasions. It has been shown by simulation and experimental results that there are operation regions for either PI or FL to give better performance while in the regions both controllers give almost the same response [8].

The present paper introduces a proposed controller scheme which explores the main idea of the fuzzy logic controller in the classical PI form. Therefore, the proposed controller combines the advantages of the classical controller techniques and the properties of the intelligent controller schemes.

The FL controller can be regarded as a set of heuristic decision rules that include the experience of a human operator. The fuzzy controller relates significant and observable variables to the control actions, and consists of a fuzzy relationship or algorithm [9]. In case of speed control, the speed error signal $\mathrm{e}(\mathrm{k})$ and its rate of change $\Delta \mathrm{e}(\mathrm{k})$ are selected as inputs to fuzzy logic controller. As a FL controller on its own is a PD (proportional plus derivative) controller equivalent [8], output of the speed FL controller is integrated in order to yield PI like behavior. Based on this fact, The CSC is designed.

\section{2- Fuzzy Logic Controller (FLC) Operation}

The FLC can be regarded as a set of heuristic decision 
rules that include the experience of a human operator. The fuzzy controller relates significant and observable variables to the control actions, and consists of a fuzzy relationship or algorithm [9]. The input error time sequences; error and change in error are converted to fuzzy variables. These variables are evaluated by the control rules using the compositional rule of inference, and approximately computed control action is then reconverted to the crisp value required to regulate the process. So the essential elements in designing fuzzy controller include [9, 15-19]:

1- Defining input and output variables.

2- Converting the input variables to fuzzy sets.

3- Determining the fuzzy control rules.

4- Reconverting the fuzzy control actions into crisp control actions.

In case of speed control, the speed error signal e(k) and its rate of change $\operatorname{de}(\mathrm{k})$ are selected as inputs to fuzzy logic controller. These are normalized into a common universe of discourse and their linguistic fuzzy subsets along with their membership grades are defined using the functions. The fuzzy membership grades of the control input change in the fuzzy subsets are obtained based on the rules given by table I. Then this normalized value of control input change is reconverted back to its actual level.

Table I. Fuzzy Control Rule Decision Table.

\begin{tabular}{|l|l|l|l|l|l|l|l|}
\hline $\begin{array}{l}\text { De(k) } \\
\text { e(k) }\end{array}$ & NB & NM & NS & ZE & PS & PM & PB \\
\hline NB & PB & PB & PB & PB & PM & PS & ZE \\
\hline NM & PB & PB & PB & PM & PS & ZE & NS \\
\hline NS & PB & PB & PM & PS & ZE & NS & NM \\
\hline ZE & PB & PM & PM & ZE & NS & NM & NB \\
\hline PS & PM & PS & ZE & NS & NM & NB & NB \\
\hline PM & PS & ZE & NS & NM & NB & NB & NB \\
\hline PB & ZE & NS & NM & NB & NB & NB & NB \\
\hline
\end{tabular}

\section{3- The Proposed SSC Design}

The following equation is suggested to represent the FL controller output in a classical form as follows:

The controller output $=$ integration of

$$
\left[k_{1}\left(e(k)+k_{2} \Delta e(k)\right)\right]
$$

Where: $\mathrm{k} 1$ and $\mathrm{k} 2$ are scaling factors.

$$
\begin{aligned}
& e(k)=\omega_{m}^{*}-\omega_{m} \\
& \Delta e(k)=\left(\omega_{m}^{*}-\omega_{m}\right)-\left(\omega_{m o}^{*}-\omega_{m o}\right) \\
& \text { If } \omega_{m}^{*} \text { is constant then: }
\end{aligned}
$$

$$
d e(k)=-\left(\omega_{m}-\omega_{m o}\right)
$$

The controller output $=$ integration of

$$
\left[k_{1}\left[\left(\omega_{m}^{*}-\omega_{m}\right)-k_{2}\left(\omega_{m}-\omega_{m o}\right)\right]\right]
$$

\subsection{The controller model}

The CSC output equation can be represented in s-domain using MATLAB/SIMULINK program as shown in Fig. 1.

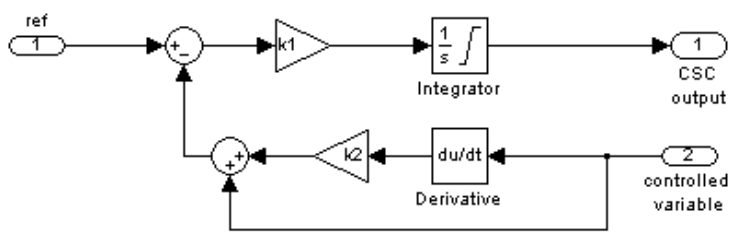

Fig.1 CSC model in s-domain.

\section{4- SRM Construction and Simulation}

The physical appearance of a switched reluctance motor highly resembles that of other conventional rotating machines (AC and DC). The construction of $8 / 6$ (8 stator poles, 6 rotor poles) poles SRM has doubly salient construction. Usually, the number of stator and rotor poles is even, and the construction is well explained in [16-20]. The windings of the SRM are simpler than those of other types of motors, and winding exists only on stator poles, and is simply wound on it with no winding on the rotor poles. The winding of opposite poles is connected in series or in parallel forming a number of phases, and exactly half the number of stator poles, and the excitation of a single phase excites two stator poles. The rotor has a simple laminated salient pole structure without winding. SRMs have the advantage of reducing copper lost while its rotor is winding. Its stampings are made preferably of silicon steel, especially in higher efficiency applications, and for aerospace application the rotor operates at very high speeds, requiring the use of cobalt, iron and other variants. The air gap is kept as minimal as possible $(0.1 \mathrm{~mm}$ to $0.3 \mathrm{~mm})$, and the rotor and stator pole arc should be kept the same. It is advantageous if the rotor pole arc is larger than the stator pole arc. The construction of an 8/6 SRM (stator and rotor) is shown in Fig. 2.
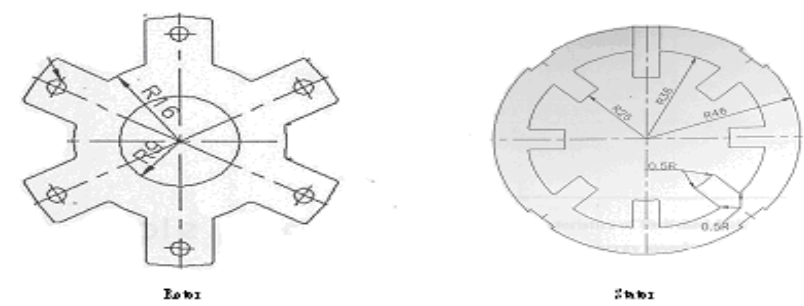

Fig.2 The SRM 8/6 poles construction.

In SRM, torque is developed because of the tendency of the magnetic circuit to adopt the configuration of 
minimum reluctance i.e. the rotor moves in line with the stator pole thus maximizing the inductance of the excited coil. The magnetic behavior of the SRM is highly nonlinear. The most general expression for the torque produced by one phase at any rotor position is

Static Torque $=T_{\text {static }}=d W^{\backslash} / d \theta$

Since

$$
\text { Coenergy }=W^{\backslash}=\int \psi(\theta, i) . . d i
$$

Where

$$
\text { Flux.linkage }=\psi(\theta, i)=\int(V-R i) d t
$$

And

$$
d \omega / d t=\left(T(\theta, i)-T_{\text {mech }}\right) / J
$$

$$
\text { Displacement.angle }=\theta=\int \omega . . d t
$$

These equations show that the developed torque depends on the magnitude of the current, flux linkage and the displacement angle of SRM.

\section{5- Photovoltaic System powered SRM}

Photovoltaic (PV) power systems convert sunlight into electricity directly. Research and development efforts are under way to improve efficiency and reduce cost of photovoltaic power systems in applications ranging from roof-top residential to large industrial or electric utility sites. Using of PV power in drive system application are increasing these days from directly coupling with the dc motors to sophisticated ac motor drive systems. SRM is one of these motors that need to supply its phases with dc current one phase at a time. The current is fed to the motor via buck boost $\mathrm{dc} / \mathrm{dc}$ converter with variable duty ratio to extract the maximum power of the PV system and fed the motor with necessary voltage and current to overcome the motor speed and torque requirements [21-22].

\section{Determination of the SSC Parameters}

Considering the Electromechanical equation of SRM:

$$
T_{e}(t)=J \frac{d \omega_{r}(t)}{d t}+B \omega_{r}+T_{L}(t)
$$

Considering the above equation, a block diagram for SRM can be obtained shown in Fig. 3:

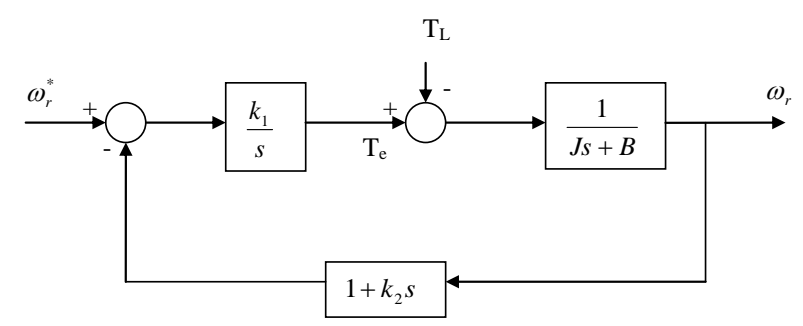

Fig. 3 Block diagram representation of SRM

Fig. 3 shows that the motor characteristics equation is given by:

$$
J s^{2}+k_{1} k_{2} s+k_{1}=0
$$

Where

$$
k_{2}=2 \sqrt{\frac{J \eta}{k_{1}}}
$$

Where $\eta$ is the damping ratio.

Alternatively, the SRM with the control loops can be drawn as shown in Fig. 4:

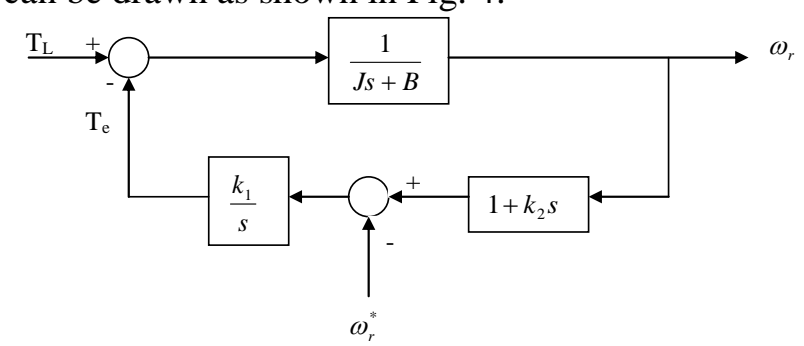

Fig. 4 Load Torque Speed block diagram of SRM

From Fig. 4, the relation between the motor speed and load torque can be obtained as follows:

$$
\omega_{r}(s)=\frac{\frac{1}{k_{1} * k_{2}}}{\frac{J}{k_{1} * k_{2}} s+1} T_{L}(s)
$$

For a step change of load torque the motor speed can be calculated as:

$$
\omega_{r}(s)=\frac{\frac{1}{k_{1} * k_{2}}}{\frac{J}{k_{1} * k_{2}} s+1} \frac{T_{L}(s)}{s}
$$

This represents a first order equation with a gain equals to:

$$
\mathrm{M}_{\text {dip }}=\frac{T_{L}}{k_{1} * k_{2}}
$$


Equation 16 represents the maximum dip in motor speed when the load torque changes from no load to full load. During this period, the controller tries to reject this disturbance. Based on equations (14) and (16), the SSC parameters can be calculated to add positive damping and full load torque rejection with a predefined maximum dip.

Equation (16) shows that increasing $(\mathrm{k} 1 * \mathrm{k} 2)$ increases the load torque disturbance rejection and Mdip becomes smaller.

\section{Results and discussions}

The controller is implemented using a high speed SRM which has an inertia constant $\mathrm{J}=0.0018 \mathrm{~kg} . \mathrm{m} 2,15$ $\mathrm{Nm}$ full load torque and is able to run at $13700 \mathrm{RPM}$. First, the controller parameters are obtained as follows:

Defining a $20 \mathrm{rad} / \mathrm{sec}$ as a maximum dip for a $15 \mathrm{Nm}$ full load disturbance and a critically damped speed response for a step change in thereference speed, the SSC parameters are calculated as follows:

$$
\begin{aligned}
& k_{1} * k_{2}=\frac{T_{L}}{M_{d i p}}=\frac{15}{20}=0.75 \\
& k_{2}=2 \sqrt{\frac{J}{k_{1}}}=2 \sqrt{\frac{J k_{2}}{0.75}} \\
& k_{2}=\frac{4 * J}{0.75}=\frac{4 * 0.0018}{0.75}=0.0096 \\
& k_{1}=\frac{0.75}{k_{2}}=\frac{.0 .75}{0.0096}=78.125
\end{aligned}
$$

The motor is operated with the proposed controller using the above values of the SSC parameters. Fig 5 shows the speed response to a step change in load torque load torque at $\mathrm{t}=0.30 \mathrm{sec}$. The disturbance is removed at $\mathrm{t}$ $=0.60 \mathrm{sec}$. The four phase's instantaneous current and torque are also shown in Fig. 6. A successive step change in load torque is also shown in Fig. 7 while the phases,s currents are given in Fig. 8. More over, the results of a full load rejection test are given in Figs 9-10. These results show fast recovery of actual speed in about $0.1 \mathrm{sec}$ and critically damped response and ensures that the calculated SSC parameters can ensure a fast response and critically damped response with a maximum dip equals the predefined value.

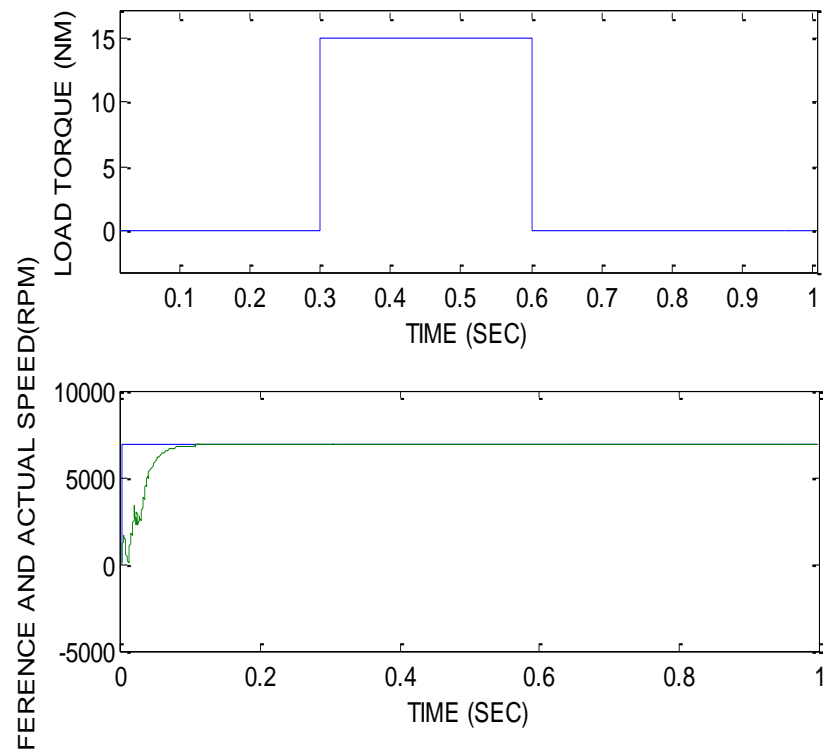

Fig. 5 Response to a Step change of load torque

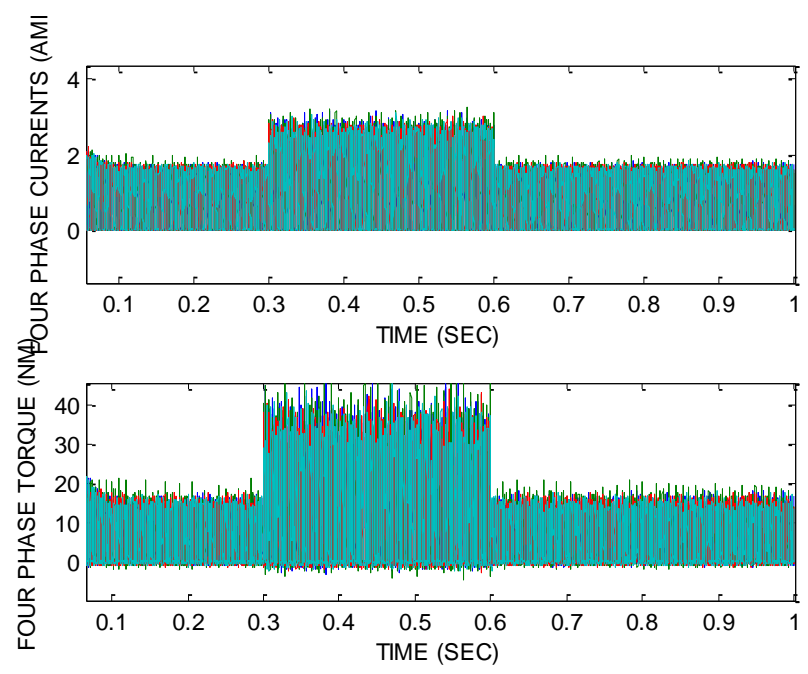

Fig. 6 Four phase's current response 

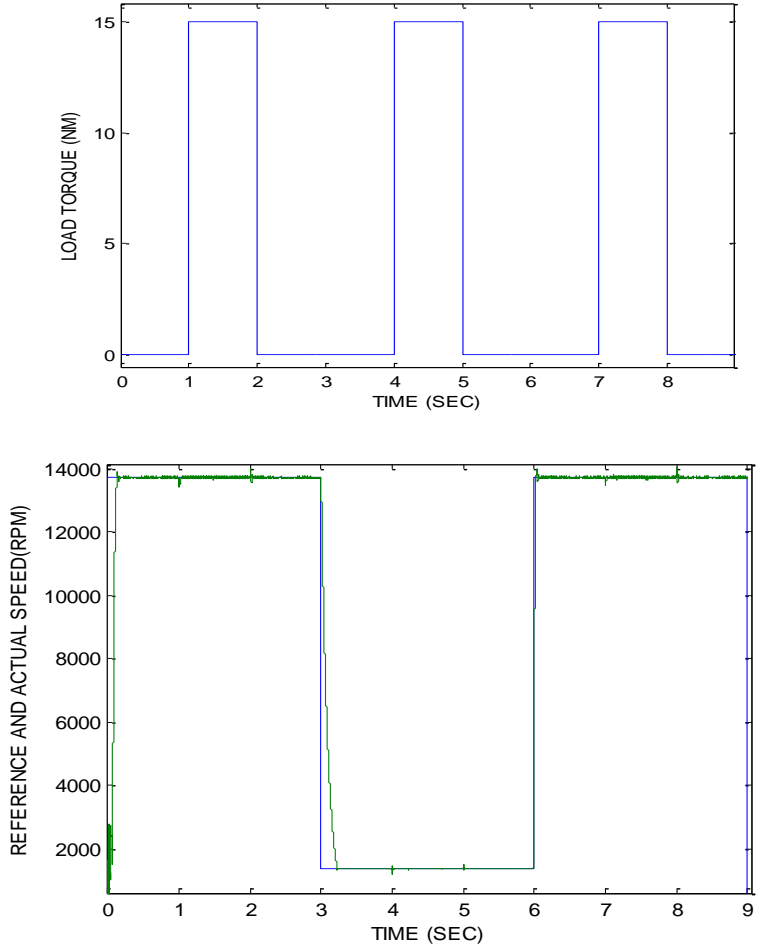

Fig. 7 Response to successive load change.

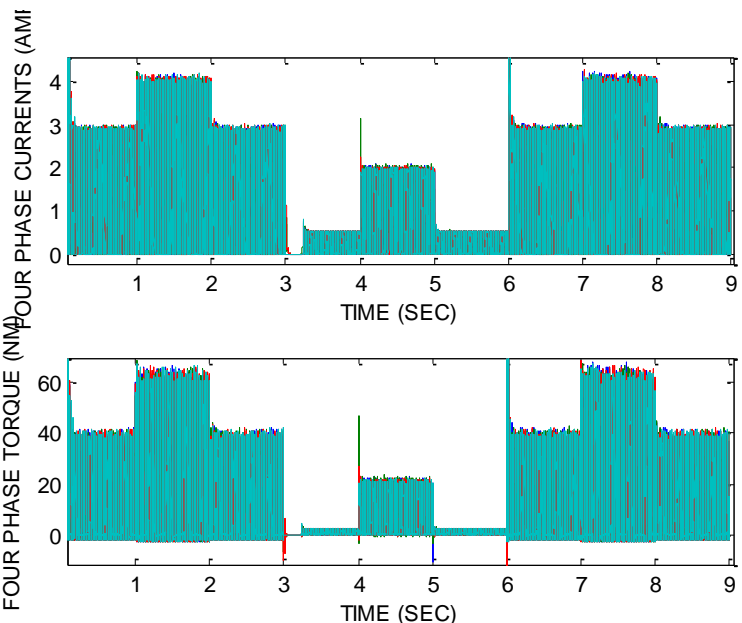

Fig. 8 Four phases current.

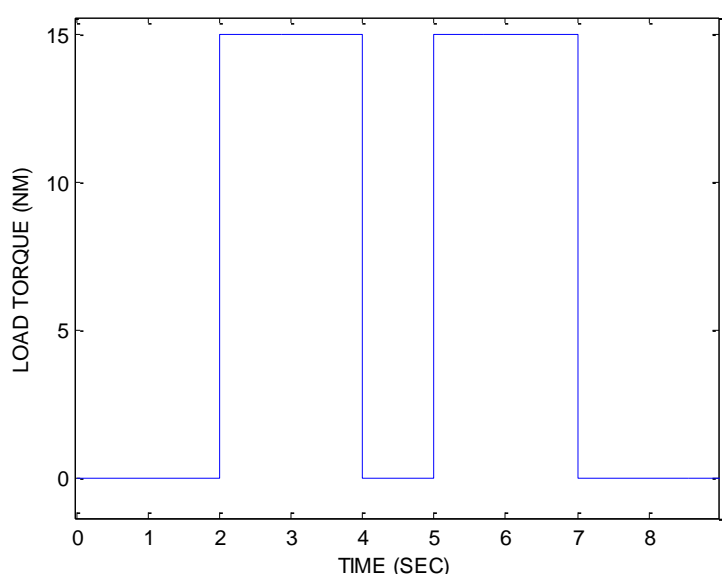

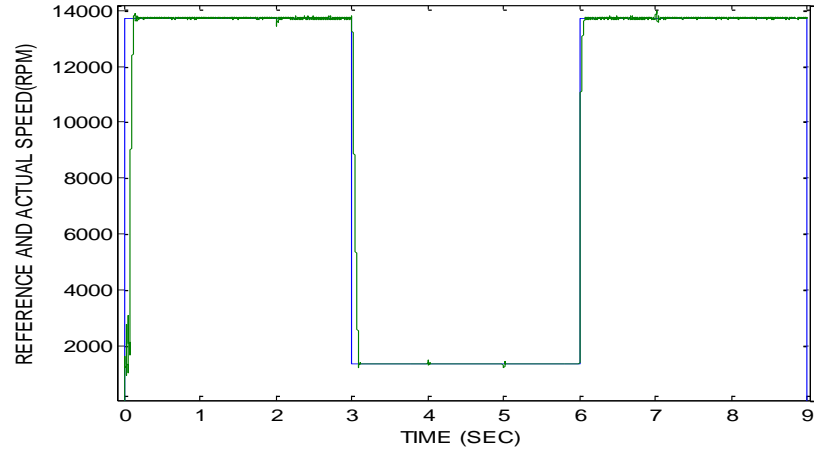

Fig. 9 Response to full load rejection

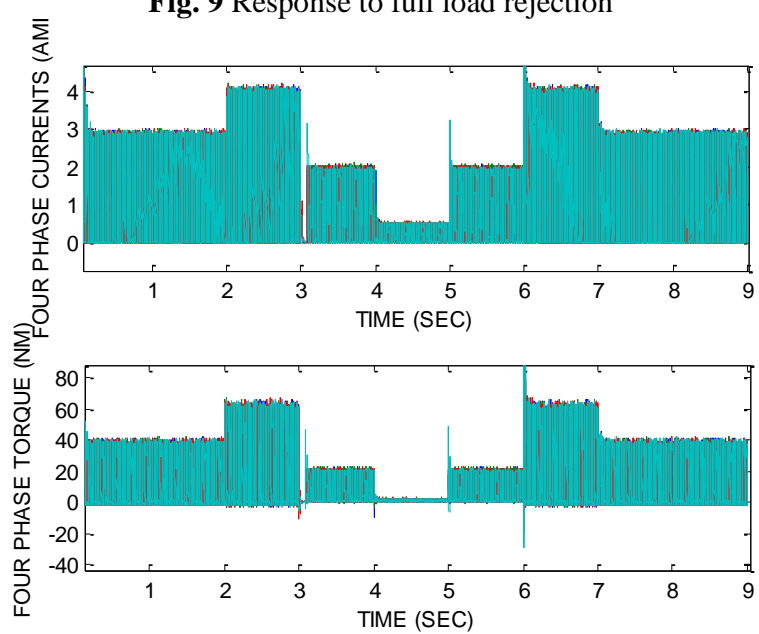

Fig. 10 Four phases current.

\section{9-Conclusions}

This paper introduced a simplified Speed controller (SSC) for high speed SRM which combines the advantages the simplicity of conventional controller and intelligence feature of the fuzzy logic controller. The SSC is simulated in s-domain using the MATLAB/SIMULINK program. The SSC parameters are calculated based on the motor mechanical equation and a predefined system performance. The SSC is applied to an accurate sensorless speed control technique for SRM high speed (13700 RPM) (8/6 poles) (four phases) model.

The SSC is used to control the motor speed at variable load torque and to change the input voltage for SRM by adjusting the duty ratio for the PV DC/DC converter supplied. Speed responses for a variety of operating conditions are studied. Simulation results show that, at all the operating conditions, the SSC reacts as an intelligent controller to provide the required system performance. 


\section{0-References}

[1] B. K. Bose, "Power electronics on ac drives", Englewood Cliffs, New Jersey: Prentice-Hall, 1986.

[2] B. K. Bose, "Microcomputer control of power electronics and drives", New York, IEEE Press 1987.

[3] Fayez El-Sousy and M. M. Salem, "Robust neural network controllers for indirect field orientation control of induction machine drive system", Proceedings of the 2002 International Conference on Control and Application, Xiamen, China, pp.1263-1268, June 2002.

[4] Ahmed Rubaai and M. Kankam, "Adaptive tracking controller for induction motor drives using on-line training of neural networks" IEEE Trans. Industrial Appl., vol. 36, no. 5, Sep./Oct. 2000.

[5] A. Brikwedde, "On-Line adaptation and self-tuning control for complex electrical drives systems", In EPE Proceeding, Aachen, , Metallurgy, Germany, 1989.

[6] B. K. Bose, "Expert systems, fuzzy logic, and neural networks applications in power electronics and motion control”, Proc. IEEE, vol. 82, pp. 1303-1323, Aug. 1994.

[7] P. Vas, "Artificial-Intelligent based electric machines and drives", New York: Oxford Univ. Press, 1999.

[8] Z. Ibrahim, and E. Levi, "A Comparative analysis of fuzzy logic and pi speed control in high-performance ac drives using experimental approach" IEEE Trans. On Industry Appl., Vol. 38, no. 5, Sep/Oct 2002.

[9] S. I. Amer and M. M. Salem, "A Comparison of different intelligent control techniques for a pmdc motor", Journal of Power Electronics, vol. 5, no. 1, January 2005

[10] B. K. Bose, "Modern power electronics and ac drives", New Jersey: Prentice-Hall, 2002.

[11] P.J. Lawrenson and J.M. Stephenson "Variable-Speed Switched Reluctance Motors" IEE Proc. Vol. 127, Pt. B. No. 4, July 1980, pp. 253-265.

[12] Khwaja M. Rahman, Suresh Gopalakrishnan, Babak Fahimi, Anandan Velayutham Rajarathnam and M. Ehsani "Optimized Torque Control of Switched Reluctance Motor at All Operational Regimes Using Neural Network" IEEE Transations on Industry Applications, vol. 37, NO. 3, May/June 2001, pp. 904-913.

[13] Krzysztof Russa, Iqbal Husain and Malik E. Elbuluk
“A Self-Tuning Controller for Switched Reluctance Motors" IEEE Transactions on power electronics, vol. 15,No.3,May2000.

[14] Naayagi R. T. \& Kamaraj V. (2005). "Shape Optimization of Switched Reluctance Machine for Aerospace Applications", Proceedings of 31st Annual Conference of IEEE Industrial Electronics Society, pp. 1748-1751, ISBN 0-7803-9252-3, Raleigh, November 2005, IEEE Industrial Electronics Society, Los Alamitos.

[15] Liu W. \& Song S. (2006). "Application of Fuzzy Control in Switched Reluctance Motor Speed Regulating System", Proceedings of International Conference on Computational Intelligence for Modelling, Control and Automation, pp. 72-72, ISBN 0-7695-2731-0, Sydney, November 2006, Patrick Kellenberger, Sydney.

[16] Dan Jones,"Present and future applications of switched reluctance motors and drives", SMIC'99 conference, October 1999, Tokyo, Japan.

[17] J.M. Stephenson and J. Corda "Computation of Torque Current in Double Salient Reluctance Motors From Nonlinear Magnetization Data" proceedings IEE,vol.126, No.5,May 1979, pp. 393-396.

[18] J. Corda and J.M. Stephenson "Analytical Estimation of the Minimum and Maximum Inductances of a Double-Salient Motor" Proceedings of the International Conference on Stepping Motors and Systems, University of Leeds, UK, September 1979, pp. 50-59.

[19] Shuyu Cao, and K.J. Teseng, "A New Method for Accurate Analytical Modeling of Switched Reluctance Motor" PEDES'98 Vol. II, December 1998 pp.540-545.

[20]Ahmed Oshaba, "Analysis and Control of SRM", Ph.D. Thesis, Cairo Univ., FOE, April, 2004.

[21] Yousry Atia, "Photovoltaic Maximum Power Point Tracking Using SEPIC Converter", Engineering Research Journal (ERJ), Shebin El-Kom Journal, Vol.36, No.4, October 2009.

[22] M. Zahran, A. Hanafy, 0. Mahgoub and M. Kamel, "FLC Based Photovoltaic Battery Diesel Hybrid System Management and Control", 28th IEEE Photovoltaic Specialists Conference", September 15-22, 2000, Anchorage Hilton, Anchorage, Alaska, USA, 0-7803-5772-(C) 2000 IEEE 